CASE REPORT

\title{
Genotype-phenotype correlation in a family with primary cortisol resistance: possible modulating effect of the ER22/23EK polymorphism
}

\author{
Hussein Raef ${ }^{1}$, Essa Y Baitei ${ }^{2}$, Minjing Zou ${ }^{2}$ and Yufei Shi ${ }^{2}$ \\ Departments of ${ }^{1}$ Medicine and ${ }^{2}$ Genetics, King Faisal Specialist Hospital and Research Centre, PO Box 3354, Riyadh 11211, Saudi Arabia \\ (Correspondence should be addressed to H Raef; Email: hraef@kfshrc.edu.sa; Y Shi; Email: yufei@kfshrc.edu.sa)
}

\begin{abstract}
Objective: Glucocorticoid resistance is a rare sporadic or familial condition that is characterized by generalized, partial resistance to glucocorticoids. It is caused by a mutation in the glucocorticoid receptor- $\alpha(\mathrm{GR}-\alpha)$ gene. We aimed to understand the reasons for different phenotypes (severe to asymptomatic) observed in a family with primary cortisol resistance.

Design: The genotype leading to cortisol resistance in the family members was investigated and correlated to the clinical phenotype.

Method: Three siblings were presented with clinical cortisol resistance, featuring severe hypertension, hypokalemia and hyperandrogenism. Three other siblings and both parents were asymptomatic. Genomic DNA from peripheral lymphocytes was isolated from family members. The entire GR- $\alpha$ coding sequence (exons 2-9) was amplified by PCR and sequenced.

Results: A homozygous G679S mutation was present in the three clinically affected subjects. Heterozygous G66A (E22E) and G68A (R23K) polymorphisms and G2035A (G679S) mutation were found in the father and two siblings. Mother and one sibling had only heterozygous G679S mutation. The clinically unaffected subjects showed two different responses to dexamethason. Those with heterozygous G679S mutation and ER22/23EK polymorphism had normal cortisol suppression, whereas those with only heterozygous G679S mutation failed to suppress normally. Conclusions: A homozygous G679S mutation of the GR- $\alpha$ gene is associated with severe cortisol resistance, whereas a heterozygous mutation of the same gene can lead to subclinical cortisol resistance. The effect of the heterozygous mutation was abolished in subjects carrying the ER22/23EK polymorphism.
\end{abstract}

European Journal of Endocrinology 158 577-582

\section{Introduction}

Glucocorticoids are vital steroid hormones with a wide spectrum of functions. These functions are largely mediated through the glucocorticoid receptor (GR). The GR binds glucocorticoid hormones in the cell cytoplasm, translocates to the nucleus, and regulates gene expression $(1,2)$. Glucocorticoid resistance is a rare sporadic or familial condition that is characterized by generalized, partial resistance to glucocorticoids, usually without clinical evidence of hyper- or hypocortisolism. Affected individuals will have compensatory elevation in adrenocorticotrophin (ACTH) and cortisol levels that fail to suppress normally by dexamethasone. The effect of very high cortisol levels on renal tubules and the increase in mineralocorticoids due to excessive ACTH stimulation will typically result in hypertension and hypokalemic alkalosis. Excess androgens could result in precocious puberty in affected males and hirsutism and irregular menses in affected females. Irritability and weakness were also reported as symptoms in affected individuals. The clinical picture can vary from mild to severe (3-6).

The molecular mechanism of primary cortisol resistance has been attributed to mutations in the ligandbinding domain (LBD) or the DNA-binding domain of the human GR- $\alpha$ gene. At present, five different mutations have been identified in five different kindreds: C1844T (V571A), A2054T (D641V), G2317A (V729I), T2373G (I747M), and a 4-bp deletion at the $3^{\prime}$ boundary of exon 6 . In addition, five more mutations were described in sporadic cases: G1430A (R477H), G2035A (G679S), T1808A (I559N), T2318C (L773P), and T2209C (F737L) (7-13). The genotype has been identified as either homozygous mutation with autosomal recessive or heterozygous mutation with autosomal dominant transmission in the familial cases. All the sporadic cases have been identified as heterozygous mutations.

The variable phenotypes among patients of primary cortisol resistance were explained by different functional 
defects caused by different mutations, even when they affect the same domain (for example the LBD) of the GR- $\alpha$. Although all such mutations in the LBD would lead to a decrease in ligand-binding affinity, some mutations were associated with delayed translocation to the nucleus after exposure to ligand (V571A, D641V, V729I, R477H, and G679S) or delayed interaction with certain coactivators (I559N, V571A, D641V, V729I, and I747M) (7-13). The ability of a heterozygous GR- $\alpha$ gene mutation (I559N and I747M) to exert a dominantnegative effect on the transcriptional activity of wildtype GR- $\alpha$ was due to the inhibition of nuclear translocation of the wild-type receptor (14).

In the present report, we describe a family with primary cortisol resistance affecting three members severely. Two other members have only abnormal dexamethasone suppression without clinical findings.

\section{Patients and methods}

\section{Case presentation}

The index patient was a 19-year-old male with longstanding history of severe uncontrolled hypertension and intractable hypokalemia since early childhood. He also had history of precocious puberty. He was misdiagnosed previously as a case of congenital adrenal hyperplasia. He was on large doses of nifedipine, atenolol, enalapril, and aldactone, in addition to dexamethasone (1 mg) daily. The family history revealed hypertension, irregular menses, and hirsutism in his two sisters. Another sister died at an early age (information is not available). Both parents, who were first-degree cousins, were reported to be normotensive and asymptomatic. On physical examination, he was slightly irritable and his blood pressure was sustained at or higher than 220/140 mmHg. Chemical analysis revealed persistent hypokalemia, kaliuresis, and renal impairment due to hypertensive nephropathy (serum creatinine 200-300 $\mu \mathrm{mol} / \mathrm{l}$, normal: 65-115). Table 1 summarizes his hormonal profile. Laboratory results were consistent with severe cortisol resistance. An escalating dose of dexamethasone up to $10 \mathrm{mg}$ three times daily was able to partially suppress the patient's endogenous cortisol and improve his blood pressure. On this dose, morning cortisol was down to $380 \mathrm{nmol} / \mathrm{l}$ and urine-free cortisol to $290 \mathrm{nmol} /$ day. His creatinine on this treatment increased initially with an increase in potassium level to $6 \mathrm{mmol} / \mathrm{l}$, but came back to a stable level with a potassium level of $4.6 \mathrm{mmol} / \mathrm{l}$.

\section{Clinical and laboratory studies}

The clinical and laboratory evaluations of family members including history, physical examination, chemistry profile, and a standard $1 \mathrm{mg}$ overnight dexamethasone suppression test were done. In the clinically affected members, more detailed hormone profiles were carried out including urine-free cortisol, morning cortisol, ACTH, aldosterone, renin, deoxycorticosteroids (DOCs), testosterone, and $17-\mathrm{OH}$ progesterone.

\section{Detection of GR- $\alpha$ gene mutation}

Genomic DNA from peripheral lymphocytes was isolated from affected members as well as healthy subjects of the family following standard procedure.

The entire coding region (exons 2-9) of the human GR- $\alpha$ gene and intron-exon boundaries were amplified in nine separate PCRs as previously described (13). Each successfully amplified fragment was directly sequenced using the BigDye Terminator V3.1 Cycle Sequencing kit (Applied Biosystems, Foster City, CA, USA), and samples were run on the ABI prism 3100 sequencer (Applied Biosystems). The study was approved by the research advisory council and the ethics committee of our center. Informed consents were obtained from all subjects.

Table 1 Clinical features and hormonal profiles of the index case and two clinically affected sisters.

\begin{tabular}{|c|c|c|c|c|c|c|c|c|}
\hline Subject (age) & $\begin{array}{l}\text { Clinical } \\
\text { findings }\end{array}$ & $\begin{array}{c}24 \text { h urine } \\
\text { free cortisol } \\
\text { (100-379; } \\
\text { nmol/day) }\end{array}$ & $\begin{array}{c}\text { ACTH } \\
\text { (up to } \\
46 ; n g / l)\end{array}$ & $\begin{array}{c}\text { Renin } \\
(0.84-2.5 ; \\
\mu \mathrm{g} / \mathrm{l} \text { per } \mathrm{h})\end{array}$ & $\begin{array}{l}\text { Aldosterone } \\
\text { (up to 831; } \\
\text { pmol/l) }\end{array}$ & $\begin{array}{l}\text { DOC } \\
(0-5 ; \\
\mu g / l)\end{array}$ & $\begin{array}{c}\text { Testosterone } \\
(\mathrm{nmol} / \mathrm{l})\end{array}$ & $\begin{array}{c}\text { 17-OH } \\
\text { progesterone } \\
(0.8-12 ; \\
\mathrm{nmol} / \mathrm{l})\end{array}$ \\
\hline $\begin{array}{l}\text { Index case } \\
\text { (19 years) }\end{array}$ & $\begin{array}{l}\text { HTN, hypokalemia, } \\
\text { PB }\end{array}$ & 2851 & 116 & 0.09 & 274 & 4 & $31(10-24)$ & 10 \\
\hline $\begin{array}{l}\text { Sibling } 6 \\
\text { (21 years) }\end{array}$ & $\begin{array}{l}\text { HTN, hirsutism and } \\
\text { LM }\end{array}$ & 2338 & 207 & 0.36 & 285 & 6 & 7.7 (up to 2.2) & 16 \\
\hline $\begin{array}{l}\text { Sibling } 7 \\
\text { (23 years) }\end{array}$ & $\begin{array}{l}\text { HTN, } \\
\text { hypokalemia, } \\
\text { hirsutism, } \\
\text { virilization } \\
\text { and LM }\end{array}$ & 4709 & 175 & $<0.03$ & 215 & 6 & 11 (up to 2.2) & 19 \\
\hline
\end{tabular}

PB, precocious puberty; LM, late menarche. Hormonal values indicate very high urine cortisol levels with elevated ACTH and suppressed renin, consistent with severe glucocorticoid resistance. Elevated $17 \mathrm{OH}$ progesterone, deoxycorticosteroids (DOCs), and testosterone are also noted in affected sisters (Siblings 6 and 7). Normal ranges are in parenthesis and abnormal values are in bold. 


\section{Results}

\section{Family phenotype}

The index patient's two sisters (siblings 6 and 7, age 21 and 23 respectively) had severe clinical and biochemical features of cortisol resistance with severe hypertension, marked hirsutism, and irregular menses. In the older sister (sibling 7), persistent hypokalemia and virilization were also noted (Table 1). The index patient's mother (age 43) and one of his brothers (sibling 4, age 18) showed no clinical signs of cortisol resistance but had biochemical evidence of such resistance (failure to suppress cortisol by $1 \mathrm{mg}$ overnight dexamethason suppression test; Fig. 2). On the other hand, the patient's father (age 45) and two of his brothers (siblings 2 and 3, age 10 and 12 respectively) did not show any evidence of cortisol resistance clinically or biochemically (normal suppression; Fig. 2).

\section{Genotype analysis}

A homozygous G2035A mutation, changing glycine to serine (G679S) was found in the index patient and his two clinically affected sisters (siblings 6 and 7). All other family members carried a heterozygous G679S mutation (Fig. 1A). In the father and two siblings (siblings 2 and 3), a heterozygous G679S mutation was found together with two previously reported G66A (E22E) and G68A (R23K) polymorphisms (Fig. 1B). The mother and one sibling (sibling 4) had only the heterozygous mutation (Fig. 1B). The distribution of alleles carrying G679S mutation and ER22/23EK polymorphism among family members are shown in Fig. 2. All the family members with the homozygous G679S mutation (index patient and siblings 6 and 7) demonstrated typical severe clinical and biochemical features of cortisol resistance (Table 1). In family members with heterozygous G679S mutation and without ER22/23EK polymorphism (mother and sibling 4), elevated cortisol levels following dexamethasone suppression test were observed: $305 \mathrm{mmol} / \mathrm{l}$ for mother and $203 \mathrm{mmol} / \mathrm{l}$ for sibling 4 (normal:< $50 \mathrm{mmol} / \mathrm{l}$; Fig. 2). Interestingly, among family members with both heterozygous G679S mutation and ER22/23EK polymorphism (father, siblings 2 and $3)$, the dexamethasone suppression test was normal (Fig. 2), indicating a possible modulating effect of the ER 22/23EK polymorphism on cortisol resistance caused by the G679S mutation.

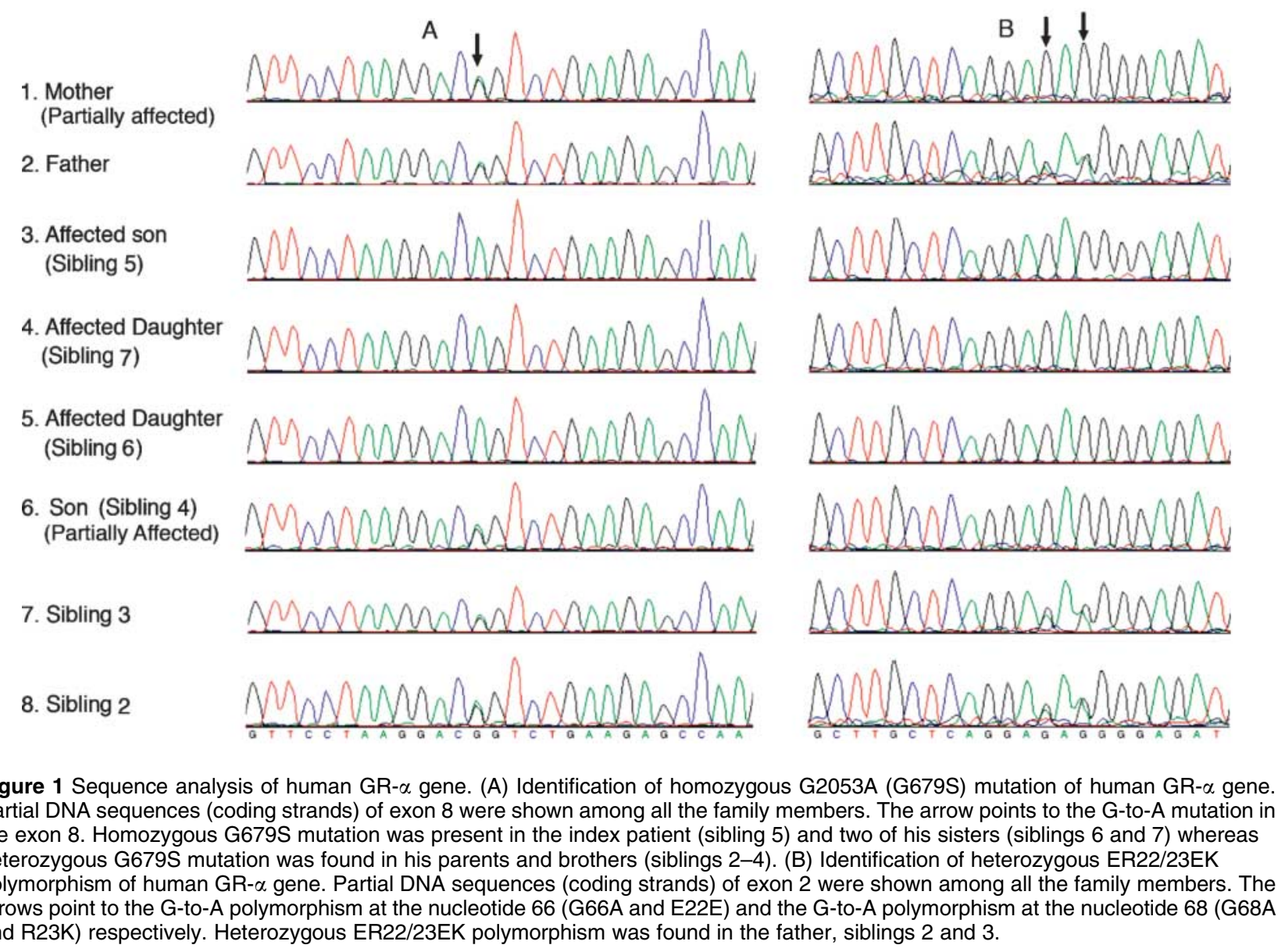

www.eje-online.org 


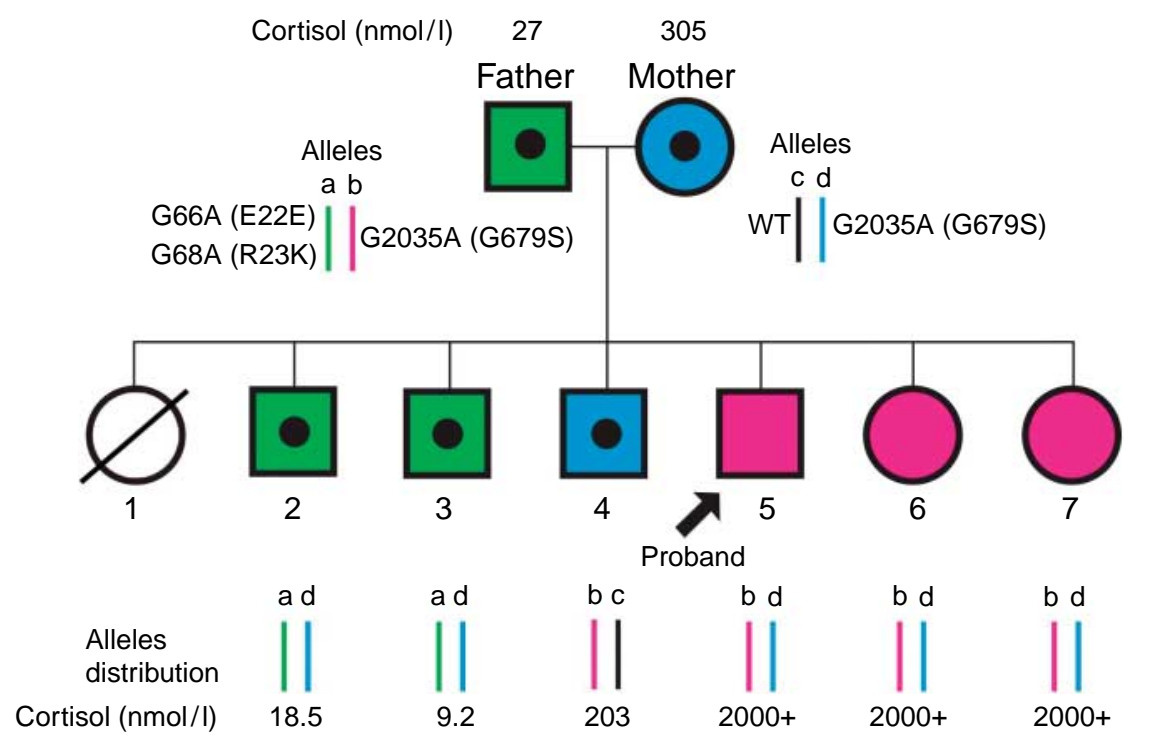

Figure 2 Family pedigree, allele distribution, and serum cortisol level after standard dexamethasone suppression test in affected and non-affected family members in a kindred of primary cortisol resistance. Both father and mother are heterozygous carriers of G679S mutation. Father has allele a (carry ER22/23EK polymorphism) and allele b (carry G679S mutation). Mother has allele $c$ (wild-type WT) and allele d (G679S mutation). The deceased sister died at early age (genetic and medical information is not available).

\section{Discussion}

A heterozygous G679S mutation was previously reported in one sporadic case of a young female presenting with hirsutism. She had an increased excretion of urinary cortisol and subnormal suppression of serum cortisol after dexamethasone (7). The mutation was mapped to the LBD of the GR- $\alpha$ gene and was caused by a point mutation at nucleotide 2035 in exon 8 (GGT to AGT), changing glycine to serine (G679S) (7). A following study showed no dominantnegative effect of this mutation on the wild-type gene, indicating autosomal recessive transmission (10). These data suggest that the wild-type allele cannot fully compensate the defect caused by G679S mutation.

We have reported the first kindred of the G2053A (G679S) mutation of the GR- $\alpha$ gene. We have shown variable phenotypes among members of a family with primary cortisol resistance. Although all members carried at least one copy of the mutation, only those with homozygous mutation had marked cortisol resistance and severe clinical features. Carriers of heterozygous G679S mutation were asymptomatic, but were different in their cortisol resistance based on an overnight dexamethasone suppression test. We observed that heterozygous carriers without ER22/23EK polymorphism had abnormal suppression and therefore subclinical cortisol resistance, whereas those who carried the ER22/23EK polymorphism had normal suppression. This unexpected finding could suggest an interaction of the polymorphism with the mutated gene copy, where the polymorphism may mitigate the effect of the mutated gene. Our data also confirm that wild-type allele cannot fully compensate the heterozygous G679S mutation. The reason that our heterozygous family members did not present clinical phenotype is probably due to individual difference in glucocorticoid sensitivity.

Examples of functional influence of single or multiple polymorphisms on the effect of a nearby mutated gene are rare, but nevertheless reported (15-19). For example, in hereditary thrombotic thrombocytopenic purpura due to mutation in the ADAMTS13 gene, the polymorphisms R7W and Q448E - that were shown to have positive modifying effect on the gene function in the absence of the mutation - enhanced the detrimental effect of the missense mutation (16). A polymorphism that mitigates the effect of a nearby mutation was also reported (17-19). In the instance of the cardiac sodium channel gene (SCN5A) mutation T512I that results in cardiac arrhythmias, the polymorphism H558R that is located on the same allele of the same gene was shown to attenuate the sodium current defect caused by the mutation (17). Two other examples of favorable modulation effect against a deleterious mutation by a polymorphism were reported in the DNA polymerase $\gamma$ gene and in the medium-chain acyl-CoA dehydrogenase gene $(18,19)$. Our finding of a possible modulating effect of the ER22/23EK polymorphism on the G679S mutation on the second allele of the same gene is therefore unique and interesting.

The ER22/23EK polymorphism in codons 22 and 23 of exon 2 of the GR- $\alpha$ gene was reported with frequency of $8-9 \%$ in elderly Dutch population (20). It is linked to lower glucocorticoid sensitivity and is associated with favorable metabolic profile (20-23). Carriers of this polymorphism tend to have lower fasting insulin and low density lipoprotein (LDL) cholesterol levels (21-23) and may have survival advantage (24). The lower cortisol sensitivity in the polymorphism carriers was attributed in one study to a lower transactivating capacity of the GR (25), and in another 
study to increased expression of less transcriptionally active GR-A isoform (26). Our finding of normal cortisol sensitivity in patients with ER22/23EK polymorphism and heterozygous G679S mutation - based on standard $1 \mathrm{mg}$ dexamethason suppression test - cannot therefore be explained by the direct effect of the polymorphism on cortisol sensitivity, since it would be expected to result in lower cortisol sensitivity.

The molecular mechanisms of cortisol resistance in the presence of G679S mutation of the GR- $\alpha$ gene were studied in vitro $(7,10)$. In addition to the decreased affinity for the ligand when compared with the wildtype GR- $\alpha$, the mutant receptors demonstrated delayed nuclear translocation, and impaired interaction of the activation function (AF)-2 domain of the receptor with the glucocorticoid receptor interacting protein (GRIP)-1 coactivator (10). The $\mathrm{Kd}$ of GR- $\alpha$ G679S is about twofold higher than that of the GR- $\alpha$-wild-type (WT) $(\mathrm{WT}=0.3 \mathrm{nM}$ and $\mathrm{G} 679 \mathrm{~S}=0.7 \mathrm{nM}$ for triamcinolon acetonide (7) and $\mathrm{WT}=8.8 \mathrm{nM}$ and $\mathrm{G} 679 \mathrm{~S}=14.8 \mathrm{nM}$ for dexamethasone (10)). Given that the difference in $\mathrm{Kd}$ between WT and G679S is relatively small and massive glucocorticoid resistance in G679S homozygous patients, it is likely that the reduced affinity may not be the major cause of glucocorticoid resistance in these patients. The delayed nuclear translocation and impaired interaction of the AF-2 domain of the receptor with the GRIP-1 coactivator might be the most important consequence of this mutation.

The possible modulating effect of the ER22/23EK polymorphism on the G679S mutation cannot be simply explained by improving the mutant receptor binding or its transactivation capacity, since it was shown to have no significant effect on the GR- $\alpha$ binding and rather a negative effect on transactivation (25). Since the G679S mutation abolishes interaction between AF2 and GRIP-1, one possible explanation for the observed phenotype might be due to GR heterodimers (G679S/ER2223EK) in the heterozygous patients. It is possible that the presence of the ER2223EK variant somehow stabilizes the impaired interaction of the complex with GRIP-1 through the AF1 domain. It is also possible that it is not ER 22/23EK which causes the effect, but some other presently unknown factor on the gene that co-inherits with ER22/23EK. Further studies will be needed to confirm these hypotheses

In our patients with homozygous G679S mutation, serum, and urinary cortisol levels were extremely high, as well as androgens and some other steroid precursors. Aldosterone was not elevated in spite of suppressed renin activity due to the effect of very high cortisol on aldosterone receptors in renal tubules, which is likely to be the primary cause of the severe hypertension in our patients. Treatment of patients with cortisol resistance is based on suppressing endogenous ACTH by exogenous steroids. Small-to-moderate doses of dexamethasone or other synthetic steroids are usually used. In severe cases higher doses are needed, but the literature is quite sparse on appropriate treatment and the results of treatment in such cases. In our index patient, $30 \mathrm{mg}$ dexamethasone in three divided doses was required to normalize ACTH, serum, and urine cortisol levels and to improve blood pressure control. One sister required $24 \mathrm{mg}$ dexamethasone in three divided doses to bring her androgen to an acceptable level, whereas her younger sister - who had milder hyperandrogenism - required only $12 \mathrm{mg}$ dexamethasone in three divided doses. Therefore, even among those with homozygous mutations, a degree of variability in phenotypes can be seen.

In summary, we have reported the first kindred of the G2053A (G679S) mutation of the GR- $\alpha$ gene. This mutation resulted in clinically severe glucocorticoid resistance only in homozygous subjects. In heterozygous carriers of this mutation, evidence of cortisol resistance was seen in subjects who did not have ER22/23EK polymorphism. Our study supports an autosomal recessive inheritance with the wild-type allele of GR- $\alpha$ gene compensating, at least partially, for the defect caused by the mutation. We have also demonstrated a positive modulating effect of the ER22/23EK polymorphism on the mutated gene on the other allele.

\section{Acknowledgements}

We thank Dr Mohammad Ahmed for his critical review of this manuscript and his valuable comments. We would also like to thank Dr Jan W Koper for his valuable discussions. This study was partially presented as an abstract at the Endocrine Society Annual Meeting, Toronto, June, 2007. The research was funded by a grant from King Faisal Specialist Hospital and Research Centre. There is no conflict of interest that would prejudice its impartiality.

\section{References}

1 Zhou J \& Cidlowski JA. The human glucocorticoid receptor: one gene, multiple proteins and diverse responses. Steroids $2005 \mathbf{7 0}$ 407-417.

$2 \mathrm{Lu}$ NZ \& Cidlowski JA. The origin and functions of multiple human glucocorticoid receptor isoforms. Annals of the New York Academy of Sciences $2004 \mathbf{1 0 2 4} 102-123$.

3 Charmandari E, Kino T \& Chrousos GP. Familial/sporadic glucocorticoid resistance: clinical phenotype and molecular mechanisms. Annals of the New York Academy of Sciences 2004 $1024168-181$.

4 Kino T, Vottero A, Charmandari E \& Chrousos GP. Familial/sporadic glucocorticoid resistance syndrome and hypertension. Annals of the New York Academy of Sciences $2002970101-111$.

5 Kino $\mathrm{T} \&$ \& Chrousos GP. Glucocorticoid and mineralocorticoid resistance/hypersensitivity syndromes. Journal of Endocrinology 2001169 437-445.

6 Lamberts SW. Hereditary glucocorticoid resistance. Annales d'Endocrinologie 200162 164-167. 
7 Ruiz M, Lind U, Gafvels M, Eggertsen G, Carlstedt-Duke J, Nilsson L, Holtmann M, Stierna P, Wikstrom AC \& Werner S. Characterization of two novel mutations in the glucocorticoid receptor gene in patients with primary cortisol resistance. Clinical Endocrinology $200155363-371$.

8 Charmandari E, Kino T, Souvatzoglou E, Vottero A, Bhattacharyya N \& Chrousos GP. Natural glucocorticoid receptor mutants causing generalized glucocorticoid resistance: molecular genotype, genetic transmission, and clinical phenotype. Journal of Clinical Endocrinology and Metabolism 200489 1939-1949.

9 Charmandari E, Raji A, Kino T, Ichijo T, Tiulpakov A, Zachman K \& Chrousos GP. A novel point mutation in the ligand-binding domain (LBD) of the human glucocorticoid receptor (hGR) causing generalized glucocorticoid resistance: the importance of the $\mathrm{C}$ terminus of hGR LBD in conferring transactivational activity. Journal of Clinical Endocrinology and Metabolism 200590 3696-3705.

10 Charmandari E, Kino T, Ichijo T, Zachman K, Alatsatianos A \& Chrousos GP. Functional characterization of the natural human glucocorticoid receptor (hGR) mutants hGRalphaR477H and hGRalphaG679S associated with generalized glucocorticoid resistance. Journal of Clinical Endocrinology and Metabolism 2006 91 1535-1543.

11 Vottero A, Kino T, Combe H, Lecomte P \& Chrousos GP. A novel, C-terminal dominant negative mutation of the GR causes familial glucocorticoid resistance through abnormal interactions with p160 steroid receptor coactivators. Journal of Clinical Endocrinology and Metabolism $2002872658-2667$.

12 De Lange P, Koper JW, Huizenga NA, Brinkmann AO, De Jong FH, Karl M, Chrousos GP \& Lamberts SW. Differential hormone-dependent transcriptional activation and -repression by naturally occurring human glucocorticoid receptor variants. Molecular Endocrinology $1997111156-1164$.

13 Mendonca BB, Leite MV, De Castro M, Kino T, Elias LL, Bachega TA, Arnhold IJ, Chrousos GP \& Latronico AC. Female pseudohermaphroditism caused by a novel homozygous missense mutation of the GR gene. Journal of Clinical Endocrinology and Metabolism 200287 1805-1809.

14 Kino T, Stauber RH, Resau JH, Pavlakis GN \& Chrousos GP. Pathologic human GR mutant has a transdominant negative effect on the wild-type GR by inhibiting its translocation into the nucleus: importance of the ligand-binding domain for intracellular GR trafficking. Journal of Clinical Endocrinology and Metabolism $2001865600-5608$.

15 Garenc C, Couillard C, Laflamme N, Cadelis F, Gagne C, Couture P, Julien P \& Bergeron J. Effect of the APOC3 Sst I SNP on fasting triglyceride levels in men heterozygous for the LPL P207L deficiency. European Journal of Human Genetics 200513 1159-1165.

16 Plaimauer B, Fuhrmann J, Mohr G, Wernhart W, Bruno K, Ferrari S, Konetschny C, Antoine G, Rieger M \& Scheiflinger F. Modulation of ADAMTS13 secretion and specific activity by a combination of common amino acid polymorphisms and a missense mutation. Blood $2006 \mathbf{1 0 7} 118-125$.

17 Viswanathan PC, Benson DW \& Balser JR. A common SCN5A polymorphism modulates the biophysical effects of an SCN5A mutation. Journal of Clinical Investigation $2003111341-346$.
18 Nielsen KB, Sorensen S, Cartegni L, Corydon TJ, Doktor TK, Schroeder LD, Reinert LS, Elpeleg O, Krainer AR, Gregersen N, Kjems J \& Andresen BS. Seemingly neutral polymorphic variants may confer immunity to splicing-inactivating mutations: a synonymous SNP in exon 5 of MCAD protects from deleterious mutations in a flanking exonic splicing enhancer. American Journal of Human Genetics $2007 \mathbf{8 0} 416-432$.

19 Chan SS, Longley MJ \& Copeland WC. Modulation of the W748S mutation in DNA polymerase gamma by the E1143G polymorphismin mitochondrial disorders. Human Molecular Genetics 2006 15 3473-3483.

20 Van Rossum EF, Koper JW, Huizenga NA, Uitterlinden AG, Janssen JA, Brinkmann AO, Grobbee DE, De Jong FH, Van Duyn CM, Pols HA \& Lamberts SW. A polymorphism in the glucocorticoid receptor gene, which decreases sensitivity to glucocorticoids in vivo, is associated with low insulin and cholesterol levels. Diabetes 200251 3128-3134.

21 Van Rossum EF \& Lamberts SW. Polymorphisms in the glucocorticoid receptor gene and their associations with metabolic parameters and body composition. Recent Progress in Hormone Research 200459 333-357.

22 Van Rossum EF, Voorhoeve PG, Te Velde SJ, Koper JW, DelemarreVan De Waal HA, Kemper HC \& Lamberts SW. The ER22/23EK polymorphism in the glucocorticoid receptor gene is associated with a beneficial body composition and muscle strength in young adults. Journal of Clinical Endocrinology and Metabolism $2004 \mathbf{8 9}$ 4004-4009.

23 Van Rossum EF, Roks PH, De Jong FH, Brinkmann AO, Pols HA, Koper JW \& Lamberts SW. Characterization of a promoter polymorphism in the glucocorticoid receptor gene and its relationship to three other polymorphisms. Clinical Endocrinology 200461 573-581.

24 Van Rossum EF, Feelders RA, Van Den Beld AW, Uitterlinden AG, Janssen JA, Ester W, Brinkmann AO, Grobbee DE, De Jong FH, Pols HA, Koper JW \& Lamberts SW. Association of the ER22/23EK polymorphism in the glucocorticoid receptor gene with survival and C-reactive protein levels in elderly men. American Journal of Medicine 2004117 158-162.

25 Russcher H, Smit P, Van Den Akker EL, Van Rossum EF, Brinkmann AO, De Jong FH, Lamberts SW \& Koper JW. Two polymorphisms in the glucocorticoid receptor gene directly affect glucocorticoid-regulated gene expression. Journal of Clinical Endocrinology and Metabolism $2005905804-5810$.

26 Russcher H, Van Rossum EF, De Jong FH, Brinkmann AO, Lamberts SW \& Koper JW. Increased expression of the glucocorticoid receptor-A translational isoform as a result of the ER22/23EK polymorphism. Molecular Endocrinology 200519 $1687-1696$.

Received 26 November 2007

Accepted 26 November 2007 